\title{
THROMBOCYTOSIS: A RETROSPECTIVE STUDY OF 573 DOGS (2016-2017)
}

\section{TROMBOCITOSE: UM ESTUDO RETROSPECTIVO EM 573 CÃES (2016-2017)}

\author{
Marcela Natacha Aparecida Rocha ${ }^{1 *}$ ORCID - http://orcid.org/0000-0002-1875-7699 \\ Mayara Carvalho de Sousa Rocha1 ORCID - http://orcid.org/0000-0002-7530-1911 \\ Mayara Lima Kavasaki ${ }^{1}$ ORCID - http://orcid.org/0000-0001-6206-039X \\ Juliana Yuki Rodrigues ${ }^{1}$ ORCID - http://orcid.org/0000-0001-8840-1420 \\ Weyber Ferreira de Souza ${ }^{1}$ ORCID - http://orcid.org/0000-0003-2305-3896 \\ Adriane Jorge Mendonça1 ORCID - http://orcid.org/0000-0002-9367-5028
}

${ }^{1}$ Federal University of Mato Grosso, Cuiabá, MT, Brazil.

*Author to correspondence - marcelanatachavet@gmail.com

\begin{abstract}
Thrombocytosis refers to the increase in number of platelets per microliter $(\mu \mathrm{L})$ of blood. Platelet counts greater than $1,000,000 / \mu \mathrm{L}$ may be associated with clinical signs of bleeding or thrombosis. Previous studies on underlying causes of thrombocytosis have aroused the interest of researchers about its clinical importance in dogs. The objective of this study was to analyze the blood cell counts in dogs in order to define the main diseases or clinical conditions that were associated with thrombocytosis, from 2016 to 2017. This was done to determine the incidence of thrombocytosis, and categorize the increase in platelet count with respect to severity. Of the 12,676 blood samples analyzed, $4.5 \%$ presented thrombocytosis $(n=573)$. Similar mean platelet counts were observed in all diagnosis or different categories of clinical conditions (neoplasms; gastrointestinal, endocrine, and ophthalmological diseases; trauma and surgery; dermatological, cardiac, neurological, infectious, respiratory, genitourinary, idiopathic, and multiple diseases; and pregnancy) with no significant difference $(\mathrm{P} \geq 0.05)$. The disorders most commonly associated with thrombocytosis were gastrointestinal diseases, followed by neoplasms. Furthermore, increased platelet counts were observed in dogs treated with glucocorticoids and vincristine drugs. As for the degree of severity, extreme thrombocytosis occurred more frequently in the presence of gastrointestinal diseases.
\end{abstract}

Keywords: gastrointestinal disease; neoplasm; platelets; thrombosis

\section{Resumo}

A trombocitose é o aumento do número de plaquetas por microlitro $(\mu \mathrm{L})$ de sangue e contagens maiores que $1.000 .000 / \mu \mathrm{L}$ podem estar associadas a sinais clínicos de sangramento ou trombose. Estudos anteriores sobre as causas subjacentes da trombocitose tem despertado o interesse quanto a sua importância clínica em cães. O presente estudo teve como objetivo analisar hemogramas de cães, com a finalidade de definir as principais doenças ou condições clínicas associadas à trombocitose dentro do período de dois anos, determinar a incidência e ainda categorizar as contagens de acordo com a severidade do aumento de plaquetas. De 12.676 hemogramas analisados, observou-se incidência de trombocitose de 4,5\% $(\mathrm{n}=573)$. As contagens médias de plaquetas em todas as categorias de diagnósticos ou condições clínica (neoplasias, doenças gastrointestinais, endócrinas, oftalmológicas, 
traumas e cirurgias, dermatológicas, cardíacas, neurológicas, infecciosas, respiratórias, geniturinárias, idiopáticas, múltiplas e gestação) foram semelhantes, não havendo diferença significativa entre elas $(\mathrm{P} \geq 0,05)$. Os distúrbios mais comumente associados à trombocitose foram as doenças gastrointestinais seguidas de neoplasias. Além disso, os aumentos na contagem de plaquetas foram observados em cães tratados com glicocorticoides e vincristina. Quanto ao grau de severidade, a trombocitose extrema ocorreu mais frequentemente nas doenças gastrointestinais.

Palavras-chaves: doença gastrointestinal; neoplasia; plaquetas; trombose

Received on: March 5, 2018.

Accepted on: April 12, 2019.

\section{Introduction}

Platelets are cytoplasmic fragments of megakaryocytes and the third cellular component of peripheral blood after erythrocytes and leukocytes ${ }^{(1)}$. Platelet count is a diagnostic tool for assessing platelet diseases, and its analysis and evaluation allows the determination of several parameters, especially in bleeding patients or in the presence of thrombocytopenia or extreme thrombocytosis ${ }^{(2)}$. Platelet parameters and their clinical significance should not be underestimated, since approximately $90 \%$ of canine and feline diseases result from abnormalities in both platelet number and function ${ }^{(3)}$. Platelet disorders include quantitative and qualitative abnormalities ${ }^{(2)}$. The identification of increased platelet count has become more common with the routine use of automated counters in veterinary clinical laboratories, but the importance of thrombocytosis in animals has not yet been fully understood ${ }^{(4,5)}$.

Thrombocytosis is defined as the increase in number of platelets in peripheral blood above the established reference range for that species, and can be classified as primary or secondary ${ }^{(2)}$. Primary or essential thrombocytosis is a myeloproliferative disease resulting from increased platelet production $^{(2,6)}$. In humans, it may be linked to a mutation of JAK2 protein, which is a part of the thrombopoietin signaling pathway and leads to megakaryocyte proliferation ${ }^{(7)}$. The causes of this disease in animals have not been determined, and diagnosis is based on excluding other diseases, similar to the diagnosis process in humans ${ }^{(2)}$.

Secondary or reactive thrombocytosis is more common than primary thrombocytosis, and can be transient or persistent, depending on its cause. It may be a physiological response to epinephrinemediated splenic contraction (in cases of trauma, exercise, excitement, pregnancy, or delivery) or increased thrombopoiesis (reactive thrombocytosis) ${ }^{(1,2)}$, or a reaction to a disorder or disease in another part of the body due to an underlying process such as recovery of immune-mediated thrombocytopenia, neoplasms, inflammatory processes, hemolytic anemia, Hepatozoon canis infection, endocrine diseases (hyperthyroidism, hyperadrenocorticism), splenectomy (absence of sequestration), intestinal parasites, traumas, or iron deficiency ${ }^{(2,6,8)}$. Additionally, acute hemorrhage can induce transient reactive thrombocytosis, which recedes within two weeks of the hemorrhagic or surgical episode ${ }^{(9)}$, and still could possibly be induced by cytokines or $\operatorname{drugs}^{(1,2,6)}$, including epinephrine and vincristine $\operatorname{administration}^{(2)}$.

According to Hammer ${ }^{(4)}$, the most common cause of secondary thrombocytosis in dogs is neoplasia. False thrombocytosis may occur associated with the presence of cytoplasmic fragments of nucleated cells and erythrocytes, lipemia, bacteria, or cryoglobulins ${ }^{(10)}$. Furthermore, serum potassium concentration $[\mathrm{K}+]$ may be increased in vitro, characterizing pseudohyperkalemia in animals with 
thrombocytosis due to the large amount of $\mathrm{K}+$ released from platelets during coagulation ${ }^{(6)}$.

Thrombocytosis may be a benign and self-limiting incidental laboratory finding that may rarely result in hemorrhage or thrombosis. However, there is no evidence yet of a correlation between thrombosis and thrombocytosis in $\operatorname{dog} \mathrm{s}^{(2,6)}$.

Since there is limited amount of clinically relevant information on thrombocytosis in dogs, with only few studies on its prevalence, etiology and consequences ${ }^{(4,5)}$, the objective of this study was to analyze 12,676 complete blood count (CBC) samples of dogs within a period of two years (2016-2017), and select those presenting thrombocytosis. Therefore, the incidence of thrombocytosis, association with diseases or clinical conditions, and categorizing the $\mathrm{CBCs}$ according to severity of platelet increase could be evaluated.

\section{Material and methods}

We retrospectively evaluated 12,676 CBC samples of dogs treated at the Veterinary Hospital of the Federal University of Mato Grosso, Campus Cuiabá (HOVET - UFMT), from January 2016 to December 2017.

The present study was approved by the Animal Ethics Committee (AEC) of UFMT under protocol number 23108902654/2018-12, and it followed the ethical principles in animal experimentation adopted by the National Council for the Control of Animal Experimentation (CONCEA).

Blood samples with ethylenediaminetetraacetic acid (EDTA) were used for the CBCs, which were measured using an automated hematology analyzer (PocH-100iV Diff-Roche $\left.{ }^{\circledR}\right)$ to obtain erythrocyte, leukocyte, and platelet values and parameters. After collection, blood smears stained with Romanowsky staining (Rapid Pan) were used for both differential leukocyte and manual platelet count. Platelets were counted by an experienced veterinary clinical pathologist using a methodology described by Villers $^{(11)}$ for 10 randomized smear fields under $100 \mathrm{X}$ optical magnification. The mean number of platelets found was multiplied by a factor of 15,000 , thus resulting in the estimated platelet number. Samples containing fibrin and microgels in the tube wall and slides containing platelet aggregates were not included in this study.

This study included samples of male and female dogs aged between one month and 18 years. The inclusion criterion was to have a medical record with a definitive diagnosis, and at least one record of platelet count $>500 \times 10^{3} / \mu \mathrm{L}$. Animals with a history of splenectomy were excluded from the study.

Each dog was assigned to one of the following disease or clinical condition categories according to the diagnosis (Chart 1): neoplasms; gastrointestinal, endocrine, or ophthalmological diseases; trauma and surgery; dermatological, cardiac, neurological, infectious, respiratory, genitourinary, idiopathic (when thrombocytosis had no underlying diseases or processes), or multiple (with more than one disease or condition involved) diseases; and pregnancy.

Based on previous studies ${ }^{(4,5,12)}$, platelet counts were categorized according to severity of thrombocytosis: mild $\left(500-600 \times 10^{3} / \mu \mathrm{L}\right)$, moderate $\left(601-800 \times 10^{3} / \mu \mathrm{L}\right)$, severe $\left(801-1000 \times 10^{3} / \mu \mathrm{L}\right)$, and extreme $\left(>1,000 \times 10^{3} / \mu \mathrm{L}\right)$.

The reference range of platelet count in dogs was as given by Schalm et al. ${ }^{(2)}$. The collected data was analyzed using descriptive statistics, and the Kruskal-Wallis test at $5 \%$ significance $(\mathrm{P} \leq 0.05)$ in the 
R Project 3.4.3 software was performed ${ }^{(13)}$.

Chart 1. Categories of diseases or clinical conditions for classification of the animals

\begin{tabular}{|l|l|}
\hline 1 - Neoplasms & 8 - Neurological diseases \\
\hline 2 - Gastrointestinal diseases & 9 - Infectious diseases \\
\hline 3 - Endocrine diseases & 10 - Respiratory diseases \\
\hline 4 - Ophthalmological diseases & 11 - Genitourinary diseases \\
\hline 5 - Trauma and Surgery & 12 - Idiopathic diseases \\
\hline 6 - Dermatological diseases & 13 - Multiple diseases \\
\hline 7 - Cardiac diseases & 14 - Pregnancy \\
\hline
\end{tabular}

\section{Results}

A total of 12,676 canine blood samples were evaluated. Of these, 573 dogs had at least one platelet count record $>500 \times 10^{3} / \mu \mathrm{L}$, corresponding to a thrombocytosis incidence of $4.5 \%$, which were similar to the results of other studies ${ }^{(5,14)}$. However, increased thrombocytosis incidence $(7.2 \%$ and $8.5 \%$ ) was reported ${ }^{(4,12)}$, which could be because platelets were counted using different procedures, including manual hemocytometer counting, blood smear estimate, automated impedance, or laserinduced light scattering. All these methods have variable accuracy and the same animal can present different results ${ }^{(15)}$. In the present study, platelets were counted using an automated method, and further confirmed by the same experienced veterinary clinical pathologist through manual microscopic examination of the blood smear. Although hematological analyzers provide greater accuracy in platelet count, there are situations where they may generate spurious results ${ }^{(16)}$. Automated and microscopic platelet counting should be used together for better result quality and reliability ${ }^{(16-18)}$.

Of all CBC samples evaluated, seven animals $(0.05 \%$; lower incidence than the one reported by Neel et al. ${ }^{(5)}$ ) were excluded from the study because the history of splenectomy could result in an increased number of circulatory platelets, as there are many reserve platelets stored in the spleen ${ }^{(19)}$. In humans, splenectomy is a common cause of transient thrombocytosis ${ }^{(2,19)}$, but in dogs it is considered an occasional cause ${ }^{(19)}$.

Similarly to the study by Neel et al. ${ }^{(5)}$, primary thrombocytosis was not identified based on the data available in medical records; hence, all dogs, except those classified with idiopathic thrombocytosis, were classified to have secondary thrombocytosis, once they presented one or more associated diseases or conditions.

In the present study, mean platelet counts in all diagnostic categories were similar, without a significant difference $(\mathrm{P}=0.325)$ between them; however, minimum and maximum counts varied (Figure 1).

The number of dogs in each identified disease category was: neoplasms, $119(20.8 \%)$; gastrointestinal diseases, 196 (34.2\%); endocrine diseases, 06 (1.0\%); ophthalmological diseases, 09 (1.6\%); trauma and surgery, 34 (5.9\%); dermatological diseases, 15 (2.6\%); heart diseases, 11 (2.0\%); neurological diseases, $03(0.5 \%)$; infectious diseases, $57(10.0 \%)$; respiratory diseases, $8(1.4 \%)$; genitourinary diseases, 56 (9.8\%); idiopathic causes, 19 (3.3\%); multiple causes, 14 (2.4\%); and pregnancy, 26 $(4.5 \%)$. 


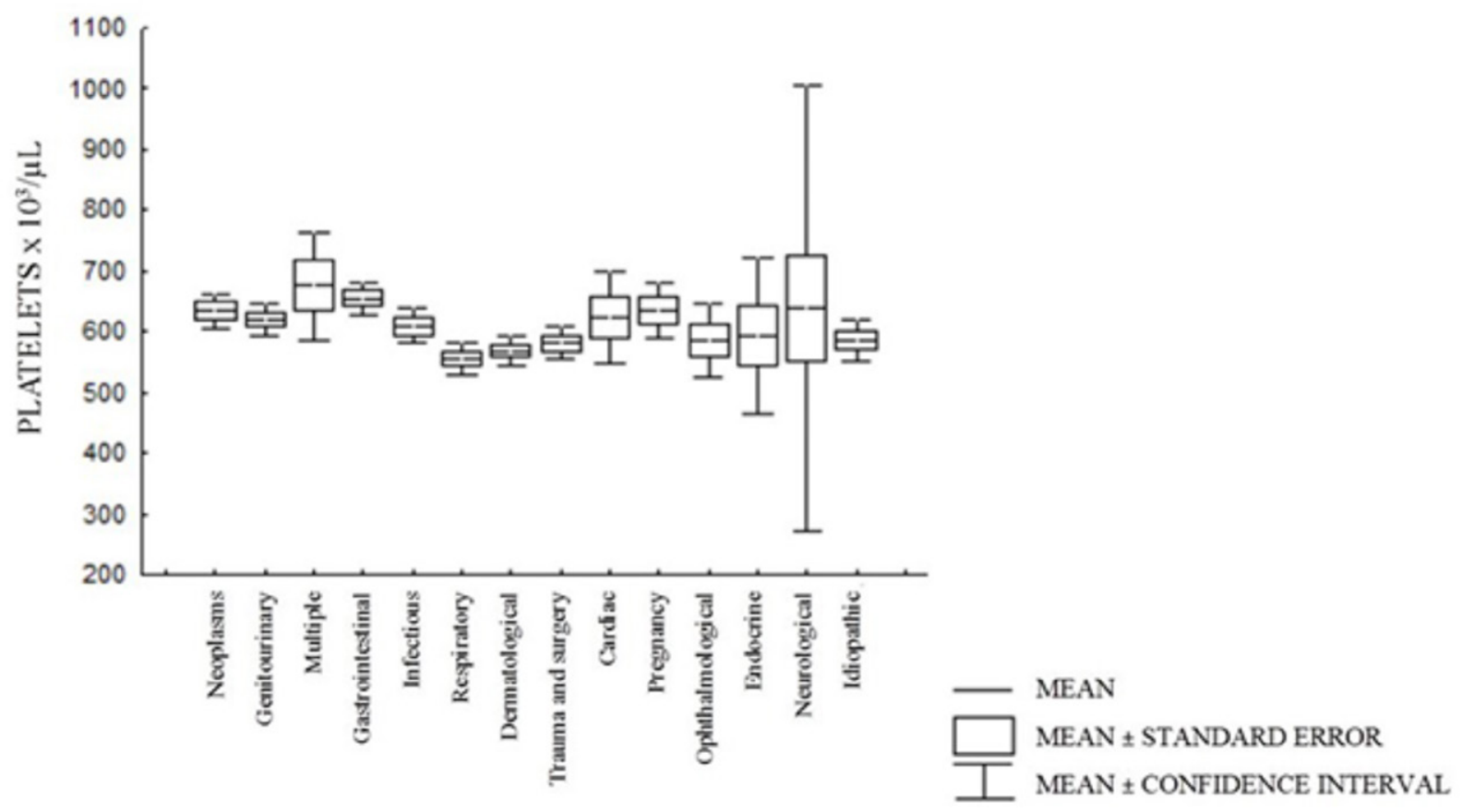

\section{DISEASE CATEGORY}

Figure 1. Box and whisker diagram showing mean, standard error, and confidence

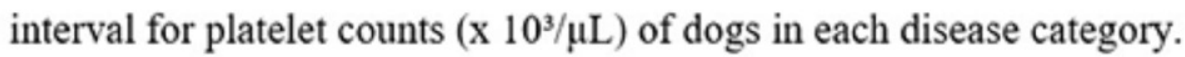

Of the included dogs, $37(6.5 \%)$ were undergoing vincristine $(n=12)$ or glucocorticoid $(n=25)$ treatment. Vincristine was used more frequently in dogs with neoplasms, including transmissible venereal tumor (TVT), lymphoma, and carcinoma, while glucocorticoids were administered for inflammatory diseases and neoplasms. These diseases are common causes of thrombocytosis. Moreover, the associated use of glucocorticoids and vincristine drugs may have increased the probability of platelet count increase due to multiple factors affecting thrombopoiesis. Stokol ${ }^{(2)}$ stated in his study that the use of these drugs could affect the platelet number, since antineoplastic agents were the most common class of agents associated with thrombocytosis. Vincristine is the most common antineoplastic agent that influences platelet production.

Increased platelet count could be quite severe under reactive conditions $(>1,000,000 / \mu \mathrm{L})^{(2)}$. When classified by severity, $311(54.2 \%)$ dogs presented mild thrombocytosis, 208 (36.3\%) moderate thrombocytosis, 43 (7.5\%) severe thrombocytosis, and $11(2.0 \%)$ extreme thrombocytosis (Table 1).

The most common diagnosis in all severity levels of thrombocytosis was infectious or inflammatory gastrointestinal disease, which differed from other studies where extreme thrombocytosis was more commonly associated with neoplasms ${ }^{(5)}$ and inflammatory diseases ${ }^{(12)}$.

Similarly to other studies ${ }^{(4,5,12)}$, carcinoma was the most common neoplastic diagnosis that affected $42(35.2 \%)$ dogs. Many studies on human carcinomas associated with thrombocytosis showed that tumors produce granulocyte-macrophage stimulating factors in addition to interleukin-6 (IL-6) and thrombopoietin ${ }^{(6,20,21)}$. The interaction between platelets and tumor cells stimulates the development of metastases, and thrombocytosis can be correlated with worse prognosis in many types of cancers ${ }^{(20)}$ that may occur in $\operatorname{dog} s^{(4,5)}$. 


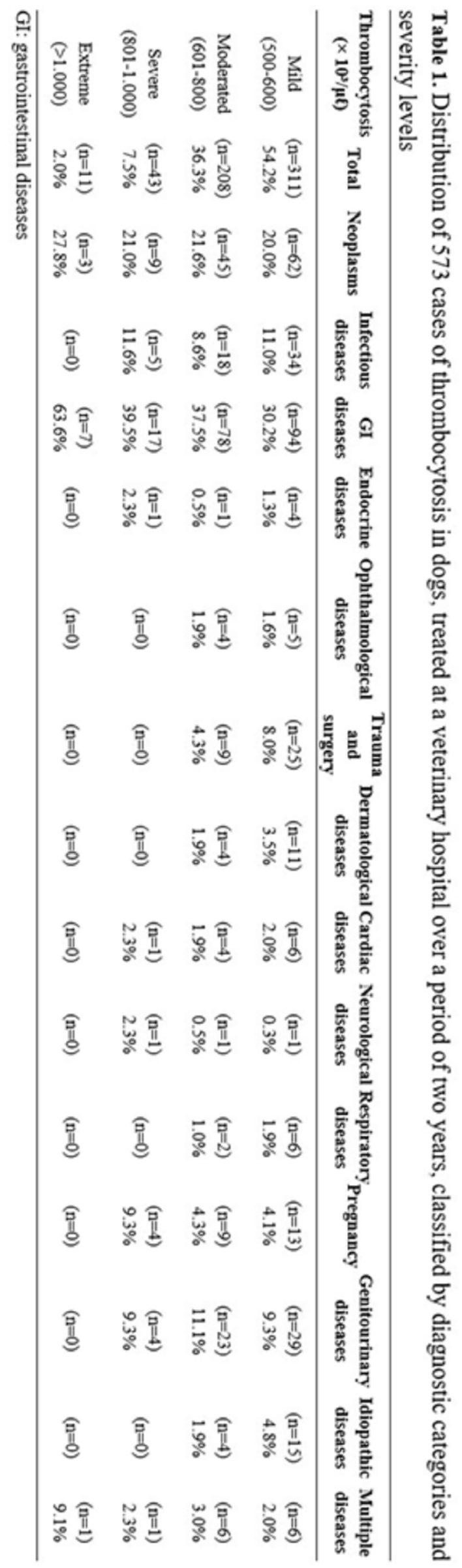


As described by Woolcock ${ }^{(12)}$, other types of neoplasms were less frequent in the present study, including adenocarcinoma $(n=7)(5.88 \%)$, adenoma $(n=5)(4.2 \%)$, hemangiosarcoma $(n=8)(6.7 \%)$, leiomyoma $(\mathrm{n}=2)(1.6 \%)$, lymphoma $(\mathrm{n}=18)(15.1 \%)$, lipoma $(\mathrm{n}=9)(7.5 \%)$, osteosarcoma $(\mathrm{n}=5)$ $(4.2 \%)$, sarcoma $(\mathrm{n}=2)(1.6 \%)$, and TVT $(\mathrm{n}=21)(17.6 \%)$. However, the association between these neoplasms and thrombocytosis is not established ${ }^{(5)}$. Vincristine and glucocorticoids were administered to 12 dogs with TVT, lymphoma, and carcinoma. This corroborated with other studies, where reactive thrombocytosis was a frequent finding in dogs with neoplastic and inflammatory diseases, and was associated with the use of glucocorticoids and vincristine ${ }^{(2,5,12)}$, because corticosteroids can increase platelet count by decreasing macrophage phagocytosis ${ }^{(2)}$, while vincristine and vinblastine can stimulate thrombopoiesis ${ }^{(2,6)}$.

Gastrointestinal diseases included infection, such as parvoviruses $(\mathrm{n}=86,43.8 \%)$; and non-infectious cases $(n=110 ; 56.1 \%)$, such as inflammation $(n=29,26.4 \%)$, parasites $(n=27,24.5 \%)$, dental causes $(\mathrm{n}=20,18.2 \%)$, hepatobiliary causes $(\mathrm{n}=21,19.1 \%)$, pancreatitis $(\mathrm{n}=6,5.4 \%)$, and food poisoning $(\mathrm{n}=7,6.4 \%)$. Gastrointestinal disorders are commonly associated with thrombocytosis in $\operatorname{dogs}^{(2)}$. In this study, diseases associated with the gastrointestinal system were more frequently associated with thrombocytosis, which was different from a study in which the frequency of gastrointestinal disorders was $19 \%{ }^{(4)}$. Most dogs in this category were diagnosed with parvoviruses, a disease that affects the gastrointestinal tract; therefore, thrombocytosis probably had multiple causes because gastrointestinal bleeding could lead to iron deficiency ${ }^{(4,6)}$ and stimulate thrombopoiesis ${ }^{(2)}$. However, serum iron concentrations were not available to diagnose iron deficiency anemia in these patients.

Similarly to other studies ${ }^{(4,5)}$, few animals presented thrombocytosis related to endocrinopathies, which were seen in three animals with hyperadrenocorticism (50\%) and three with diabetes mellitus (50\%). The correlation between thrombocytosis and diabetes mellitus is not well understood. However, some studies reported that dogs with diabetes mellitus also developed hyperadrenocorticism and increased glucocorticoid concentration, which could explain thrombocytosis in these patients ${ }^{(2)}$.

\section{Discussion}

In this study, dogs with thrombocytosis were allocated to different disease categories by organ or system, and this tended to obscure the role of infection and inflammation in thrombocytosis. In the categories of ophthalmological diseases; trauma and surgery; dermatological, cardiac and neurological diseases; neoplasms; and gastrointestinal, respiratory, and genitourinary diseases, the dogs could have been suffering from bacterial infection or associated inflammatory process. This suggests the need for a better classification scheme, but unfortunately, in a retrospective study, it is difficult to definitively determine the amount of inflammation that is associated with a neoplasm, or if thrombocytosis is due to urinary tract infection or the use of antineoplastic drugs. Moreover, as suggested by Hammer ${ }^{(4)}$, animals with thrombocytosis associated with non-localized clinical signs should be carefully evaluated for neoplasms, especially because thrombocytosis may be a significant neoplasm marker or indicator.

As for diagnosis of infectious diseases, one $\operatorname{dog}(1.7 \%)$ had brucellosis, $17 \mathrm{dogs}(29.8 \%)$ had distemper, and 39 dogs $(68.4 \%)$ had hemoparasitosis. Distemper is often associated with thrombocytopenia due to increased levels of antiplatelet antibodies, and is considered an immune-mediated thrombocytopenia with platelet removal by the monocytic phagocytic system ${ }^{(22)}$. This immune-mediated thrombocytopenia may justify thrombocytosis in the studied dogs, since thrombocytopenia recovery may cause rebound thrombocytosis; therefore, the production exceeds loss, with consumption or destruction after hemorrhage or elimination of the myelosuppressive agent ${ }^{(2,6)}$. Of the 17 dogs with distemper, nine 
$(52.9 \%)$ presented thrombocytopenia during the first platelet count, of which seven $(77.8 \%)$ presented severe thrombocytopenia suggesting rebound thrombocytosis.

Of the dogs that presented thrombocytosis associated with genitourinary diseases, $25(44.6 \%)$ had chronic kidney disease. Uremia can cause abnormal platelet function, changing the interaction between platelets and vessel walls ${ }^{(12)}$. Thrombocytosis in humans with renal disease may indicate greater disease severity ${ }^{(23)}$. However, in veterinary medicine, there are no scientific investigations on thrombocytosis as a prognostic marker for renal disease. However, in this category, 31 female dogs $(55.3 \%)$ presented pyometra, which has varied mechanisms involved in increase in platelets related to inflammatory processes mediated by cytokines (especially IL-6) that stimulate thrombopoiesis ${ }^{(2,4)}$.

When no underlying symptom or diagnosis was identified, the cause of thrombocytosis was considered idiopathic. Increased platelet counts do not necessarily mean the presence of a disease, and may be detected in routine CBCs. Additionally, false thrombocytosis may occur associated with the presence of cytoplasmic fragments of nucleated cells and erythrocytes, lipemia, bacteria, or cryoglobulins ${ }^{(10)}$. In humans, primary or essential thrombocytosis is a clonal myeloproliferative disease originating from stem cells that may be associated with other chronic myeloproliferative diseases, such as chronic myeloid leukemia, polycythemia vera, and primary myelofibrosis ${ }^{(24)}$. The causes of this disease in animals have not been determined. Therefore, like in humans, the diagnosis is based on excluding the presence of other disorders ${ }^{(2)}$, and on a complete evaluation to ensure that it is not a case of secondary thrombocytosis ${ }^{(6)}$.

As for pregnancy, seven female dogs $(26.9 \%)$ had dystocia. In these cases, thrombocytosis may have occurred as a physiological response caused by epinephrine-mediated splenic contraction ${ }^{(2,6)}$.

A potentially misleading consequence of thrombocytosis is pseudohyperkalemia ${ }^{(6)}$ that occurs in serum samples due to the release of intracellular $\mathrm{K}+$ during coagulation. Increased $\mathrm{K}+$ concentration may be proportional to platelet increase, with higher concentrations in dogs with extreme thrombocytosis $(>1,000,000 \text { platelets } / \mu \mathrm{L})^{(2)}$.

In humans, thrombocytosis increases the risk of thromboembolic events, especially in cases of primary thrombocytosis and uremia ${ }^{(12)}$. Thrombocytosis also affects prognosis and survival in neoplasms and other diseases ${ }^{(12,23)}$. Due to lack of information in the medical records analyzed, this study did not investigate the potential for thromboembolic events in the studied dogs, nor did it investigate survival or outcomes after treatments. Thus, future studies are necessary for such research.

\section{Conclusion}

The method used allowed us to conclude that reactive thrombocytosis had an incidence of $4.5 \%$ in the analyzed CBC samples, and were mainly associated with gastrointestinal diseases and neoplasms. Thrombocytosis was observed in dogs treated with glucocorticoids and vincristine, and extreme thrombocytosis showed more association with gastrointestinal diseases $(63.6 \%)$.

\section{References}

1. Baker DC. Diagnóstico dos distúrbios Hemostáticos. In: Thrall MA. Hematologia e Bioquímica Clínica 
Veterinária. 2nd ed. Rio de Janeiro: Roca; 2015. p. 399-439.

2. Stokol T. Essential thrombocythemia and reactive thrombocytosis. In: Weiss DJ, Wardrop K. Schalm's Veterinary Hematology, 6th ed. Iowa: Blackwell Publishing Company; 2010. p. 605-611.

3. Stokol T, Erb HN. A comparison of platelet parameters in EDTA and citrateanticoagulated blood in dogs. Vet Clin Pathol. 2007; 36(2): 148-54.

4. Hammer AS. Thrombocytosis in dogs and cats: A retrospective study. Comparative Haematology International. 1991; 1(4): 181-86.

5. Neel JA, Snyder L, Grindem CB. Thrombocytosis: a retrospective study of 165 dogs. Vet Clin Pathol. 2012; 41(2): 16-222.

6. Stokhan SL, Scott MA. Fundamentos de patologia clínica veterinária. 2nd ed. Rio de Janeiro: Guanabara Koogan; 2011.

7. Levine RL, Wadleigh M, Cools J, et al. Activating mutation in the tyrosine kinase JAK2 in polycythemia vera, essential thrombocythemia, and myeloid metaplasia with myelofibrosis. Cancer Cell. 2005; 7(4): 387-97.

8. Dan K. Thrombocytsis in iron deficiency anemia. Internal Medicine. 2005; 44(10): 1025-26.

9. Liptak JM, Dernell WS, Monnet E, et al. Massive hepatocellular carcinoma in dogs: 48 cases (1992-2002). J Am Vet Med Assoc. 2004; 225(8): 1225-30.

10. Harvey JW. Veterinary Hematology: A Diagnostic Guide and Color Atlas. Missouri: Elsevier Saunders; 2012.

11. Villers E. Introduction to haematology. In: Villers E, Ristic J. BSAVA Manual of canine and Felinae Clinical Pathology. 3rd ed. Reino unido: BSAVA; 2016. p. 27-37.

12. Woolcock A, Keenan A, Cheung C, Christian JA, Moore GE. Thrombocytosis in 715 Dogs (2011-2015). J Vet Intern Med. 2017; 31(6): 1691-99. Doi: http://dx.doi/10.1111/jvim.14831.

13. R Development Core Team (2017). R: Alanguage and environment for statistical computing. R Foundation for Statistical Computing, Vienna, Austria.

14. Athanasiou LV, Polizopoulou ZS, Papavasileiou EG, Mpairamoglou EL, Kantere MC, Rousou XA. Magnitude of reactive thrombocytosis and associated clinical conditions in dogs. Vet Rec. 2017; 181(10): 267. Doi: http://dx.doi/10.1136/vr.104042.

15. Boudreaux MK. Platelet structure. In: Weiss DJ. Wardrop K. Schalm's Veterinary Hematology. 6th ed. Iowa: Blackwell Publishing Company; 2010. p. 561-568.

16. Malok M, Titchener EH, Bridgers C, Lee BY, Bamberg R. Comparison of two platelet count estimation methodologies for peripheral blood smears. Clin Lab Sci. 2007; 20(3): 154-60.

17. Séverine T, Cripps PJ, Mackin AJ. Estimation of platelet counts on feline blood smears. Vet Clin Pathol. 1999; 28(2): 42-5.

18. Povall A, Kendrick CJ. Estimated platelet and differential leucocyte counts by microscopy, Sysmex XE2100 and CellaVisionTM DM96. N Z J Med Lab Sci. 2009; 63(1): 3-10.

19. Khan PN, Nair RJ, Olivares J, et al. Postsplenectomy reactive thrombocytosis. Proc (Bayl Univ Med Cent). 2009; 22(1): 9-12. 
20. Hwang SJ, Luo JC, Li CP, et al. Thrombocytosis: A paraneoplastic syndrome in patients with hepatocellular carcinoma. World J Gastroenterol. 2004; 10(17): 2472-77.

21. Bihari C, Rastogi A, Shasthry SM, et al. Platelets contribute to growth and metastasis in hepatocellular carcinoma. Journal of pathology, microbiology and immunology. 2016; 124(9): 776-86. Doi: http:// dx.doi/10.1111/apm.12574.

22. Mangia SH, Paes AC. Cinomose. In: Megid J, Ribeiro MG, Paes AC. Doenças Infecciosas em Animais de Produção e de Companhia. 1st ed. Rio de Janeiro:Roca. 2016. p. 560-579.

23. Forbes SH, Ashman N, Yaqoob MM. The role of platelets in the prognosis of renal disease. OA Nephrology. 2013; 1(2): 17.

24. Leite AB, Silva HF, Nogueira OL. Trombocitemia essencial. Revista brasileira de hematologia e hemoterapia. 2001; 23(1): 49-51. 